\title{
B-cell overexpression of Bcl-2 cooperates with p21 deficiency for the induction of autoimmunity and lymphomas
}

Inés Santiuste $^{1}$, Luis Buelta ${ }^{2}$, Marcos Iglesias ${ }^{1,3}$, Fernanda Genre $^{1,3}$, Francisco Mazorra ${ }^{4}$, Shozo Izui ${ }^{5}$, Jesús Merino ${ }^{1}$ and Ramón Merino ${ }^{1,3}$.

${ }^{1}$ Departmento de Biología Molecular, Instituto de Formación e Investigación Marqués de Valdecilla and ${ }^{2}$ Departmento de Ciencias Médicas y Quirúrgicas, Universidad de Cantabria, Santander, Spain; ${ }^{3}$ Instituto de Biomedicina y Biotecnología de Cantabria/CSIC-Universidad de Cantabria-IDICAN, Santander, Spain; ${ }^{4}$ Departmento de Anatomía Patológica, Hospital Universitario Marqués de Valdecilla, Santander, Spain; ${ }^{5}$ Department of Pathology and Immunology, Faculty of Medicine, University of Geneva, Geneva, Switzerland.

Correspondence: Dr. Ramón Merino, IBBTEC, Departamento de Biología Molecular, Facultad de Medicina, Cardenal Herrera Oria s/n, 39011 Santander, Spain Phone: 4942201956

Fax: 34942201945

e-mail: merinor@,unican.es 


\begin{abstract}
Genetic abnormalities predisposing to autoimmunity generally act in a cooperative manner affecting one or several mechanisms regulating immunological tolerance. In addition, many of these genetic abnormalities are also involved in the development of lymphoproliferative diseases. In the present study, we have determined the possible cooperation between deficiencies in members of the Cip/Kip family of cell cycle regulators ( $221^{\mathrm{WAF} 1 / \mathrm{Cip} 1}$ or $\mathrm{p} 27^{\mathrm{kip} 1}$ ) and the overexpression of human Bcl-2 in B lymphocytes in the induction of autoimmune and lymphoproliferative diseases in nonautoimmune C57BL/6 (B6) mice. Unlike single mutant mice, B6.p2 $1^{-/-}$mice transgenic for human Bcl-2 in B cells developed a lethal autoimmune syndrome characterized by the production of autoantibodies, the prominent expansion of memory $\mathrm{B}$ and $\mathrm{CD}^{+} \mathrm{T}$ cells and the development of severe glomerular lesions resembling IgA nephropathy. Furthermore, these mice presented a high incidence of B-cell lymphoproliferative disorders. Such genetic cooperation in the induction of autoimmunity was not observed in B6.p27 $7^{-/-}$mice transgenic for human $\mathrm{Bcl}-2$ in $\mathrm{B}$ cells. Altogether, what we have demonstrated here is the existence of preferential interactions among particular regulators of the $G_{1} / S$ transition of the cell cycle and $B$ cell survival in the induction of systemic autoimmune and lymphoproliferative diseases.
\end{abstract}

Key words: Systemic lupus erythematosus, B-cell lymphomas, p2 $1^{\mathrm{WAF} 1 / \mathrm{Cip} 1}$, p2 $7^{\mathrm{kip} 1}$, Bcl-2. 
Abreviations: Transgenic mice (Tg), human Bcl-2 (hBcl-2), systemic lupus erythematosus (SLE), C57BL/6 (B6), p21 ${ }^{\mathrm{WAF} 1 / \mathrm{Cip} 1}$ (p21), p27 $7^{\mathrm{kip} 1}$ (p27), autoantibodies (autoAbs), lymphoproliferative disorders (LPD), B6-SV40-E $\mu-h b c l-2-22$ Tg mice (B6hBcl-2-B Tg), B6.129S2-Cdkn1a ${ }^{\mathrm{tm} 1 \mathrm{Tyj} / J}\left(\mathrm{~B} 6 . \mathrm{p} 21^{-/}\right)$, B6.129S4-Cdkn1b ${ }^{\mathrm{tm} 1 \mathrm{Mlf} / J}\left(\mathrm{~B} 6 . \mathrm{p} 27^{-/-}\right.$ ), carboxyfluorescein diacetate succinimidyl ester (CFSE), bromodeoxyuridine (BrdU), gp70 anti-gp70 immune complexes (gp70 IC), wild type (wt), polymorphic LPD (PLPD), activation-induced cell death (AICD). 


\section{Introduction}

With rare exceptions, the development of autoimmune diseases requires the contribution of multiple genetic, epigenetic and environmental factors. These factors generally act in a cooperative manner affecting one or several mechanisms that regulate the induction and maintenance of immunological tolerance [1]. Among the best characterized genetic alterations involved in the development of autoimmunity, are those that affect the regulation of lymphocyte survival. Using a line of transgenic (Tg) mice overexpressing human $\mathrm{Bcl}-2(\mathrm{hBcl}-2)$ in B lymphocytes, we and others have demonstrated that $\mathrm{Tg}$ mice bearing a pro-autoimmune genetic background develop a lethal autoimmune lupus-like syndrome that is dependent on the activity of $\mathrm{CD} 4^{+}$ lymphocytes $[2,3]$. However, the overexpression of $\mathrm{hBcl}-2$ in $\mathrm{B}$ cells from $\mathrm{C} 57 \mathrm{BL} / 6$ (B6) mice, which do not have a genetic predisposition to developing the disease, fails to promote autoimmune manifestations [2], indicating that the inhibition of B lymphocyte apoptosis by itself is not sufficient to trigger a severe autoimmune reaction. Similarly, B6 mice deficient in bim or Fas fail to develop a fatal autoimmune pathology in contrast to the severe systemic lupus erythematosus (SLE) observed in mixed (129/Sv x B6)bim $^{-/}$or MRL.Fas ${ }^{l p r}$ mice, respectively [4-6].

The deregulation in the control of lymphocyte proliferation is also associated with the development of autoimmune diseases. In this sense, mice deficient in $\mathrm{p} 21^{\mathrm{WAF} 1 / \mathrm{Cip} 1}$ ( $\mathrm{p} 21$; a member of the Cip/Kip family of cell cycle inhibitors) in a line of mice with a mixed (129/Sv x B6) genetic background (derived from 2-3 intercrosses) develop a fatal lupus-like syndrome that affects females more than males [7]. Similarly, the administration of a peptidyl mimic of $\mathrm{p} 21$ into (NZB $x$ NZW)F $F_{1}$ females significantly reduces the severity of the spontaneous SLE in these animals [8]. Again, the severity of the autoimmune syndrome in $\mathrm{p} 21^{-/-}$mice appears to be modulated by the 
genetic background of the mice analyzed. Thus, B6 and BXSB mice deficient in p21 or an additional line of $\mathrm{p} 21^{-/-}$mixed (129/Sv x B6) mice, derived from an unknown number of intercrosses, are largely protected from the development of SLE [9-12]. Another member of the Cip/Kip family acting as a negative regulator of cell cycle is $\mathrm{p} 27^{\mathrm{kip} 1}$ (p27). Studies have shown that p27 plays an important role in the induction and maintenance of clonal anergy of $\mathrm{T}$ lymphocytes induced after inhibition of costimulation [13]. In anergic $\mathrm{CD}^{+} \mathrm{T}$ lymphocytes, $\mathrm{p} 27$ inhibits the phosphorylation of Smad-3 resulting in an increase of the inhibitor of Cdks, p15. Consequently, the deficiency in p27 prevents the induction of clonal anergy in $\mathrm{T}$ lymphocytes [14]. However, $\mathrm{p} 27^{-/-}$mice do not develop evident autoimmune manifestations [15].

In addition to their ability to promote autoimmunity in the context of a particular genetic predisposition, the cell cycle and apoptotic regulators mentioned above may be also involved in tumor development. In this regard, Bcl-2 was initially identified as a gene implicated in the $\mathrm{t}(14: 18)$ chromosomal translocation found in the majority of follicular B-cell lymphomas [16] and Tg mice overexpressing Bcl-2 in B cells spontaneously developed plasmacytomas or immunoblastic B-cell lymphomas albeit with a low incidence $[17,18]$. Similarly, an association between Burkitt's lymphomas and mutations in p21 that diminish the functional activity of this cell cycle regulator has been reported in humans [19], and $\mathrm{p} 21^{-/-}$mice have a higher incidence of different types of tumours, including B-cell lymphomas, in aged but not young mice [20]. More recently, it has been shown that $\mathrm{p} 27^{-/-}$mice overexpressing $\mathrm{Bcl}-2$ in $\mathrm{T}$ lymphocytes spontaneously develop T-cell lymphomas with a high incidence [21].

Based on these findings, in the present study we have determined the possible cooperation between p21 or p27 deficiency and the B-cell overexpression of Bcl-2 in the development of both lupus-like autoimmune disease and B-cell malignancies in 
normal B6 mice. Our results show that B6.p2 $1^{-/-}$mice transgenic for $\mathrm{hBcl}-2$ in B cells (B6.p21 $1^{-/-}$-hBcl-2-B Tg) developed a lethal lupus-like syndrome characterized by the production of autoantibodies (autoAbs), the increase in memory B and $\mathrm{CD}^{+}{ }^{\mathrm{T}}$ cells and the presence of severe glomerular lesions resembling an IgA nephropathy. In addition, these mice exhibited a high incidence of B-cell lymphoproliferative disorders (LPD). On the other hand, the deficiency in p27 failed to promote autoimmune responses in B6.hBcl-2-B $\mathrm{Tg}$ mice, indicating the existence of preferential interactions among particular regulators of the $G_{1} / S$ transition of the cell cycle and cell survival for the control of B-cell tolerance.

\section{Materials and methods}

\subsection{Mice}

B6 mice were obtained from Harlan Iberica (Barcelona, Spain). B6-SV40-E $\mu-$ hbcl-2-22 Tg mice (B6-hBcl-2-B Tg) [3] overexpressing hBcl-2 in B cells, B6.129S2Cdkn1 $\mathrm{a}^{\mathrm{tm} 1 \mathrm{Tyj} / \mathrm{J}}\left(\right.$ B6.p21 $\left.1^{-/}\right)$[22] and B6.129S4-Cdkn1b $\mathrm{b}^{\mathrm{tm} 1 \mathrm{Mlf} / \mathrm{J}}\left(\mathrm{B} 6 . \mathrm{p} 27^{-/}\right)$mice [15] were purchased from The Jackson Laboratories (Bar Harbor, ME). The selection of hBcl-2-B Tg mice was performed by flow cytometry using peripheral blood mononuclear cells and a specific mAb against $\mathrm{hBcl}-2$ (clone 6C8; BD Biosciences, Madrid, Spain), as described previously [23]. B6.p2 $1^{-/-}-\mathrm{hBcl}-2-\mathrm{B}$ Tg and B6.p27 $7^{-/-}$-hBcl-2-B Tg mice were obtained by intercrossing F1 progeny of B6.p2 $1^{-/-}$and B6.p2 $7^{-/-}$mice with B6-hBcl-2-B Tg mice. The $\mathrm{p} 21$ and $\mathrm{p} 27$ genotyping of the different strains of mice was performed by PCR. Male and female mice of each mouse strain were analyzed together. The mice were bled every two months from the retro-orbital plexus, and the resulting sera were stored at $-20^{\circ} \mathrm{C}$ until used. 
All studies with live animals were approved by the Universidad de Cantabria Institutional Laboratory Animal Care and Use Committee.

\subsection{Cell death and in vitro proliferation assays}

To analyze the possible modulation of $\mathrm{hBcl}-2$ anti-apoptotic activity in B cells by $\mathrm{p} 21$ or $\mathrm{p} 27$ deficiency in vivo, 2 month-old mice of the different strains used here were injected ip. with $2 \mathrm{mg}$ of dexamethasone sodium phosphate (American Regent Laboratories, Shirley, NY). The numbers of pre-B $\left(\mathrm{B}^{2} 20^{\mathrm{low}} \mathrm{IgM}^{-}\right)$and immature B $\left(\mathrm{B} 220^{\text {loww }} \mathrm{IgM}^{+}\right)$cells in the bone marrow were analyzed 48 hrs later by flow cytometry.

Purified B cells (more than 95\% purity in all cases) from different strains of mice were obtained from the spleen after in vitro treatment with anti-Thy-1.2 mAb (clone AT-83, a rat IgM anti-mouse Thy-1.2 mAb) and complement (Cedarlane Laboratories, Hornby, ON, Canada). The effects of $\mathrm{hBcl}-2$ overexpression on $\mathrm{B}$ cell survival in vitro in the different lines of $\mathrm{hBcl}-2 \mathrm{Tg}$ mice and non-Tg controls were assessed using purified cell populations cultured with RPMI medium supplemented with $2 \mathrm{mM}$ Lglutamine, $10^{-5} \mathrm{M}$ 2-mercaptoethanol and $10 \%$ heat-inactivated FCS (Hyclone Laboratories, Logan, UT), as described previously [24].

B-cell labelling with carboxyfluorescein diacetate succinimidyl ester (CFSE, Molecular Probes Europe, Leiden, The Netherlands) was performed according to the manufacturer's instructions. For in vitro proliferation assays, 2 × $10^{5}$ CFSE-labelled B cells from the different strains of mice were stimulated during $48 \mathrm{hrs}$ with LPS or an affinity-purified $\mathrm{F}\left(\mathrm{ab}^{\prime}\right)_{2}$ goat anti-mouse IgM polyclonal $\mathrm{Ab}$ (Jackson ImmunoResearch Laboratories, Inc., West Grove, PA), at concentrations of $20 \mu \mathrm{g} / \mathrm{ml}$. Cell division was analyzed by flow cytometry according to the CFSE intensity dilution. 


\subsection{Flow cytometry studies}

The number of total $\mathrm{B} 220, \mathrm{~B} 220^{+} \operatorname{IgM}{ }^{-} \operatorname{IgD}{ }^{-} \mathrm{CD} 138^{-}$(memory phenotype), naïve $\mathrm{CD} 4{ }^{+} \mathrm{CD} 44^{\text {low }} \mathrm{CD} 62 \mathrm{~L}^{\text {high }}, \quad \mathrm{CD} 4{ }^{+} \mathrm{CD} 44^{\text {high }} \mathrm{CD} 62 \mathrm{~L}^{\text {low }}$ (memory phenotype), naïve $\mathrm{CD}^{+} \mathrm{CD} 44^{\text {low }} \mathrm{CD} 62 \mathrm{~L}^{\text {high }}$ and $\mathrm{CD} 8{ }^{+} \mathrm{CD} 44^{\text {high }} \mathrm{CD} 62 \mathrm{~L}^{\text {low }}$ (memory phenotype) cells in the spleen of the different strains of mice was evaluated by flow cytometry at 2 and 8 months of age. Single cell suspensions were stained with different combinations of flourescein isothiocyanate-, phycoerythrin-, peridinin chlorophyll protein- and biotinconjugated mAbs (BD Biosciences) followed by allophycocyanin-conjugated streptavidin. A total of $5 \times 10^{4}$ viable cells were analyzed in a FACSCanto II flow cytometer using FACSDiva software (BD Biosciences).

\subsection{Serological studies}

Serum levels of total IgA and IgG were determined by ELISA as described previously $[2,25]$. Results were expressed in $\mathrm{mg} / \mathrm{ml}$ in reference to a standard curve obtained with a mouse reference serum (ICN Biomedicals Inc.). The presence of IgG and IgA anti-DNA autoAbs was determined in sera by ELISA as described $[2,25]$ and the results expressed in $\mathrm{TU}$ in reference to a standard curve obtained from a serum pool from 6-8 months old MRL lpr/lpr mice. Serum levels of IgG gp70 anti-gp70 immune complexes (gp70 IC) were quantified by ELISA [26] and the results expressed as $\mu \mathrm{g}$ of Ab-bound gp 70/ml of serum.

\subsection{Histopathology}

Samples of all major organs were obtained at autopsy. Organs were included in paraffin and stained with hematoxilin-eosin or Masson trichrome for pathological studies. Glomerulonephritis was scored on a 0 to 4 scale as previously described [27]. 
Grades 3 and 4 glomerulonephritis were considered significant contributors to clinical disease and/or death. The incidence of B-cell LPD in the different mouse strains was analyzed at 8-10 and 18 months of age by histology, immunohistochemistry and flow cytometry. All histological preparations were analyzed blinded by one (kidney sections) or two (B-cell LPD) pathologists.

Tissue-bound IgG and IgA antibodies were studied by immunofluorescence on kidney cryosections using FITC-conjugated goat anti-mouse IgG antibodies (Jackson ImmunoResearch) or FITC-conjugated goat anti-mouse IgA antibody (Cappel Laboratories, Cochranville, PA).

\subsection{Statistical analysis}

Statistical analysis of differences between groups of mice was performed using the Mann-Whitney test. Probability values $<0.05$ were considered significant.

\section{Results}

\subsection{Lack of the effect of p21 deficiency on the survival and proliferation of $B$ cells overexpressing hBcl-2}

We first determined whether p21 deficiency modulated the anti-apoptotic activity of $\mathrm{hBcl}-2$ in $\mathrm{B}$ cells from B6.p2 $21^{-/}-\mathrm{hBcl}-2-\mathrm{B} \mathrm{Tg}$ mice, as $\mathrm{p} 21$ can act as a survival factor in several cell types including T lymphocytes [reviewed in 28]. After the viability of purified B cells in culture had been assessed during a period of 10 days, B cells from both B6.hBcl-2-B Tg and B6.p21 $1^{-/-}-\mathrm{hBcl}-2-\mathrm{B} \mathrm{Tg}$ mice exhibited a similarly improved survival as compared to B cells from B6-wt and B6.p2 $1^{-/-}$mice (Figure 1A). The lack of the effect of p21 deficiency on B-cell survival was confirmed in vivo after induction of apoptosis of pre-B and immature B cells with glucocorticoids. The 
injection of dexamethasone into B6-wt and B6.p2 $1^{-/-}$mice induced the elimination of about $85 \%$ of $\mathrm{B}_{22} 2{ }^{\text {low }} \operatorname{IgM}^{-}$pre-B and $80 \% \mathrm{~B}^{2} 20^{\text {low }} \operatorname{IgM}^{+}$immature $\mathrm{B}$ cells in the bone marrow (Figure 1B). These two B-cell precursors were, however, largely preserved in dexamethasone-treated $\mathrm{B} 6 . \mathrm{hBcl}-2-\mathrm{B} \mathrm{Tg}$ mice and this protection was not modified in B6.p2 $1^{-/-}-\mathrm{hBcl}-2-\mathrm{B}$ Tg mice (Figure 1B).

It has been reported that the overexpression of Bcl-2 has an anti-proliferative effect in lymphocytes $[29,30]$. Accordingly, the in vitro proliferation of B lymphocytes from B6.hBcl-2-B Tg mice $48 \mathrm{hrs}$ after stimulation with anti-IgM antibodies or LPS was lower than that observed with B cells from B6-wt mice (Figure 1C). Although an increased in vitro anti-IgM- or LPS-induced B-cell proliferation was observed in B6.p2 $1^{-/-}$mice, the $\mathrm{p} 21$ deficiency was not sufficient to rescue the proliferative defect induced by Bcl-2 overexpression in B cells from B6.p21 $1^{-/-} \mathrm{hBcl}-2-\mathrm{B}$ Tg mice (Figure $1 \mathrm{C})$.

\subsection{Effects of B-cell overexpression of hBcl-2 in $\mathrm{p}^{2} 1^{-/-}$mice in the development of autoimmunity}

We next compared the development of a lupus-like autoimmune disease between B6-wt, B6.p21 $1^{-/}$, B6.hBcl-2-B Tg and B6.p2 $1^{-/-}-\mathrm{hBcl}-2-\mathrm{B} \mathrm{Tg}$ mice by analyzing the levels of circulating autoAbs at 6 months of age. A significant increase in serum levels of $\operatorname{IgA}$ and $\operatorname{IgG}$ anti-ssDNA autoAbs was observed in B6.hBcl-2-B Tg mice in comparison to B6-wt and B6.p2 $1^{-/-}$mice $(p<0.01$ in all cases), while levels of nephritogenic gp70 IC were essentially identical in these three strains of mice (Figure 2A). In contrast, B6.p21 $1^{-/-}$hBcl-2-B Tg mice exhibited 2-4-fold higher levels of antissDNA and gp70 IC than B6.hBcl-2-B Tg mice (Figure 2A; $p<0.005$ in all the cases). In addition, analysis of serum levels of $\operatorname{IgA}$ and $\operatorname{IgG}$ also revealed significant increases of 
IgA in B6.hBcl-2-B Tg mice, as compared with B6-wt and B6.p2 $1^{-/-}$mice $(p<0.01)$, and of both IgA and IgG in B6.p21 $1^{-/-}-\mathrm{hBcl}-2-\mathrm{B}$ Tg mice, as compared with B6.hBcl-2-B Tg mice $(p<0.005)$, (Figure 2B).

We compared by flow cytometry the distribution of $\mathrm{B}$ and $\mathrm{T}$ cell populations in spleens between B6-wt, B6.p2 $1^{-/-}$, B6.hBcl-2-B Tg and B6.p21/--hBcl-2-B Tg mice at 2 and 8 months of age. As expected, mice overexpressing hBcl-2 in $\mathrm{B}$ cells displayed a marked accumulation of B cells in B6.hBcl-2-B and B6.p21/--hBcl-2-B Tg mice (Table 1). The size of $\mathrm{B}$ cells with a memory phenotype (B200 $\left.{ }^{+} \mathrm{IgM}^{-} \mathrm{IgD}^{-} \mathrm{CD}^{-138^{-}}\right)$was greatly enlarged in 2 and 8 month-old B6.hBcl-2-B Tg mice ( $p<0.01$ and $p<0.001$, respectively) and modestly increased in B6.p2 $1^{-/-}$mice at 8 months of age $(p<0.05$; Table 1$)$. The combination of Bcl-2 overexpression and p21 deficiency appeared synergistic as the number of $\mathrm{B}^{200^{+}} \mathrm{IgM}^{-} \mathrm{IgD}^{-} \mathrm{CD} 138^{-} \mathrm{B}$ cells in B6.p21 $1^{-/-}$-hBcl-2-B Tg mice was highly increased $(p<0.05$ at 2 months and $p<0.001$ at 8 months; Table 1$)$. As reported in mixed (129/Sv x B6) mice deficient in p21 [7], an age-dependent expansion in CD4 ${ }^{+} \mathrm{T}$ cells with a memory phenotype $\left(\mathrm{CD} 4{ }^{+} \mathrm{CD} 44^{\text {high }} \mathrm{CD} 62 \mathrm{~L}^{\text {low }}\right)$ was observed in B6.p2 $1^{-/}$mice $\left(p<0.05\right.$; Table 1). Such an expansion was more pronounced in B6.p2 $1^{-/-}-\mathrm{hBcl}-2-\mathrm{B}$ Tg mice $(p<0.005)$ and already evident at 2 months of age, which was not the case in B6.hBcl-2-B Tg mice (Table 1). No differences were observed in the numbers of naïve and memory $\mathrm{CD}^{+} \mathrm{T}$ cells among these strains of mice.

In correlation with the production of auto $\mathrm{Ab}$ and the expansion of $\mathrm{B} 200^{+} \mathrm{IgM}^{-}$ IgD ${ }^{-} \mathrm{CD} 138^{-} \mathrm{B}$ and $\mathrm{CD} 4^{+} \mathrm{CD} 44^{\text {high }}{ }^{\mathrm{CD}} 62 \mathrm{~L}^{\text {low }} \mathrm{T}$ cells, B6.p21/--hBcl-2-B Tg mice had a reduced lifespan in comparison to B6-wt, B6.p2 $1^{-/-}$and B6.hBcl-2-B Tg mice (Figure 3). In fact, $50 \%$ of B6.p $21^{-/-}-\mathrm{hBcl}-2-\mathrm{B} \mathrm{Tg}$ mice died at around 16 months of age $(p<0.001)$. When examined for the cause of death, 52\% (22/42) of B6.p2 $1^{-/-}-\mathrm{hBcl}-2-\mathrm{B}$ Tg mice $(p<0.001)$ showed at the time of autopsy a severe glomerulonephritis (Figure 
4A) characterized by an intense mesangial matrix expansion, secondary to collagen accumulation (stained in blue with the Masson trichrome) that completely collapsed the capillary spaces (glomerulosclerosis) (Figure 4B). By direct immunofluorescence, prominent deposits of $\operatorname{IgA}$, but not of $\operatorname{IgG}$, were detected in the glomerular mesangium of these animals (Figure 4B). None of the B6-wt, B6.p2 $1^{-/-}$and B6.hBcl-2-B Tg mice examined showed severe glomerular lesions at 14-16 months of age (Figure 4A and B). Altogether, our results indicated the development of an IgA nephropathy associated to SLE in B6.p21 $1^{-/-}$hBcl-2-B Tg mice. Unlike mice deficient in p21 in a mixed (129/Sv x B6) genetic background which developed a lupus-like syndrome that affects females more than males [7], no differences in the levels of circulating autoAbs, memory B and $\mathrm{CD}^{+} \mathrm{T}$ cell expansion, development of glomerulonephritis and mortality rate were observed between both sexes of B6.p2 $1^{-/-}$-hBcl-2-B Tg mice (data not shown).

\subsection{Absence of a severe SLE in B6.p27 ${ }^{-/-}-\mathrm{hBcl}-2-B \mathrm{Tg}$ mice}

We further explored whether the deficiency of $\mathrm{p} 27$, another regulator of the $\mathrm{G}_{1} / \mathrm{S}$ transition of cell cycle, also cooperates with hBcl-2 overexpression in B cells for the induction of autoimmunity mice. As observed in $\mathrm{p} 21^{-/-}$mice, the deficiency in $\mathrm{p} 27$ failed to modify the survival of B cells and the anti-apoptotic activity of Bcl-2 in vitro and in vivo (Figure 1A and B). In addition, the analysis for the effects of p27 deficiency in the proliferation of $\mathrm{hBcl}-2$ overexpressing B cells showed that the reduced proliferation of B cells in mice overexpressing hBcl-2 was not restored by p27 deficiency (Figure 1C).

When the production of autoAbs in B6.p2 $7^{-/-}$mice at 6 months of age was analyzed, only the levels of circulating total $\operatorname{IgA}$ and $\operatorname{IgG}$ were slightly increased or reduced, respectively, in comparison to B6-wt and B6.p2 $1^{-/-}$mice (Figure 2; $p<0.02$ in all cases). The levels of circulating IgA and IgG anti-ssDNA autoAbs in B6.p27 $7^{-/}$-hBcl- 
2-B Tg mice were significantly elevated as compared to B6.p2 $7^{-/-}$mice $(p<0.005$ in all cases), but not higher than those of B6.hBcl-2-B Tg mice and much lower than those of

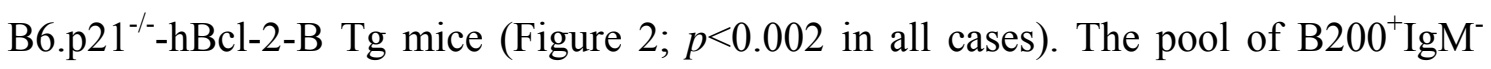
$\operatorname{IgD}^{-} \mathrm{CD} 138^{-} \mathrm{B}$ cells was increased in the spleen of 8 month-old B6.p27 $7^{-/}$and 2 and 8 month-old B6.p2 $7^{-/-}$-hBcl-2-B Tg mice in comparison to B6-wt mice, but was still lower than that of B6.p2 $1^{-/-}$-hBcl-2-B Tg mice at both 2 and 8 months of age (Table $1 ; p<0.01$ in both cases). Furthermore, B6.p2 $7^{-/-}$and B6.p2 $7^{-/-}-\mathrm{hBcl}-2-\mathrm{B}$ Tg mice also displayed an increase in the number of $\mathrm{CD} 4{ }^{+} \mathrm{CD} 44^{\text {high }} \mathrm{CD} 62 \mathrm{~L}^{\text {low }} \mathrm{T}$ cells at levels similar to that observed in B6.p2 $1^{-/-}-\mathrm{hBcl}-2-\mathrm{B} \mathrm{Tg}$ mice (Table 1). The analysis of renal histopathology at 14 months of age in B6.p2 $7^{-/-}$and B6.p2 $7^{-/-}$-hBcl-2-B Tg mice revealed that only 13\%

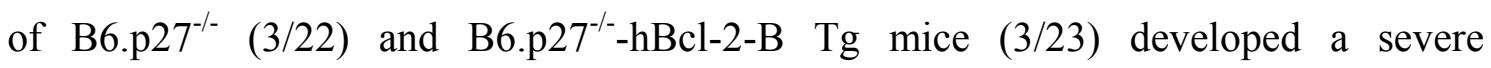
glomerulonephritis (Figure 4A and C).

\subsection{Development of B-cell LPD in B6.p21 ${ }^{-/-}-\mathrm{hBcl}-2-\mathrm{B}$ Tg mice}

Since almost half of B6.p2 $1^{-/-}-\mathrm{hBcl}-2-\mathrm{B}$ Tg mice did not show severe glomerular lesions at the time of autopsy, we explored for the presence of additional causes of death in these animals. In fact, B6.p2 $21^{-/-}-\mathrm{hBcl}-2-\mathrm{B}$ Tg mice presented an elevated incidence of B-cell LPD, evaluated by histological analysis (Figure 5 and Table 2) and immunohistochemistry and/or flow cytometry (data not shown). These malignancies were classified into two histological categories; polymorphic LPD (PLPD) composed of B cells at different stages of development/activation (small cells, immunoblasts and plasma cells) (Figure 5A and B) and monomorphic LPD resembling immunoblastic Bcell lymphomas (Figure 5C and D) showing signs of high proliferative activity such as abundant aberrant mitosis (Figure C) and a starry sky pattern (Figure 5D), indicative of the presence of macrophages phagocyting dying cells. These lymphomas usually 
formed solid peritoneal tumours and infiltrated other organs such as the liver or kidneys (Figure 5D). Some animals displayed only PLPD but the majority of mice with B-cell lymphomas also had PLPD usually in the infiltrating organs (Figure 5D and E).

To analyze in greater detail the development of LPD in B6.p2 $1^{-/-}-\mathrm{hBcl}-2-\mathrm{B} \mathrm{Tg}$ mice in comparison to B6-wt, B6.p2 $1^{-/-}$and B6.hBcl-2-B Tg mice, groups of these animals were sacrificed at 8-10 months and 18 months of age. At 8-10 months of age $31 \%$ and $44 \%$ of B6.p21 $1^{-/-}$hBcl-2-B Tg mice presented PLPD and B-cell lymphomas, respectively, in contrast to $7 \%$ of B6.p $21^{-/-}$mice presenting PLPD (Table 2). None of B6-wt and B6.hBcl-2-B Tg mice had B-cell malignancies at this age. Among the B6.p2 $1^{-/-}-\mathrm{hBcl}-2-\mathrm{B}$ Tg mice that survived up to 18 months of age, $15 \%$ and $70 \%$ of animals presented PLPD and B-cell lymphomas, respectively (Table 2). In contrast, the respective incidences were $19 \%$ and $2 \%$ in $\mathrm{B} 6 . \mathrm{p} 21^{-/-}$mice, and $0 \%$ and $17 \%$ in $\mathrm{B} 6 . \mathrm{hBcl}-$ 2-B Tg mice.

\section{Discussion}

The control of cell cycle and survival is essential for the maintenance of lymphoid homeostasis and self-tolerance. Disruption in the regulation of any of these processes in mice can lead to autoimmunity and/or LPD [1]. However, the development of pathology in these animals, particularly autoimmune diseases, is largely influenced by the genetic background of the strains of mice studied [2, 9-12]. Due to the polygenetic nature of autoimmune diseases, we have analyzed here the possible complementation between genetic defects affecting the regulation of lymphocyte survival (Bcl-2 overexpression) and proliferation (p21 or p27 deficiency) in the development of autoimmunity and LPD in mice with a non-autoinmune genetic background. We have demonstrated that the deficiency in the cell cycle regulator $\mathrm{p} 21$ 
and the overexpression of Bcl-2 in B cells in non-autoimmune B6 mice promote a lethal lupus-like syndrome characterized by autoAb production and an IgA nephropathy. This lupus-like syndrome associated to IgA nephropathy resembles that of (NZW x B6)F1 mice overexpressing $\mathrm{hBcl}-2$ in B cells [2], supporting the importance of B-cell Bcl-2 deregulation in the pathogenesis of this particular form of experimental glomerulonephritis. In addition, B6.p2 $1^{-/-}-\mathrm{hBcl}-2-\mathrm{B} \mathrm{Tg}$ mice present a high incidence of B-cell LPD. In contrast, such cooperation for the development of autoimmunity is not observed in $\mathrm{p} 27^{-/-}$mice overexpressing Bcl-2 in B cells.

Our present results confirm the importance of the pro-autoimmune genetic predisposition for the complete manifestation of autoimmunity in mice deficient in p21. Recently, it has been shown that B6.p2 $1^{-/-}$mice develop mild lupus-like serological and glomerular abnormalities that do not modify the lifespan of these animals in comparison to mice deficient in p21 in an autoimmune-prone mixed (129/Sv x B6) genetic background $[7,9]$. This contrasts with the lack of development of even a mild lupus-like syndrome in our B6.p2 $1^{-/-}$mice, and the reasons for this discrepancy may be attributed to differences in animal housing conditions or to the origin of B6 colonies used in both studies. However, the fact that B6.p2 $1^{-/-}-\mathrm{hBcl}-2-\mathrm{B} \mathrm{Tg}$ mice develop a severe lupus-like syndrome clearly supports the idea that p21 deficiency acts as an autoimmunity enhancer that cooperates with hBcl-2 overexpression in B cells, thereby triggering severe autoimmune responses in normal mice. The beneficial effects of the treatment with a peptidyl mimic of $\mathrm{p} 21$, which inhibits the interaction between cyclin-dependent kinase 4 and type $\mathrm{D}$ cyclins, on the development of SLE in $(\mathrm{NZB} \times \mathrm{NZW}) \mathrm{F}_{1}$ females [8] further support this idea. In contrast, other studies in BXSB mice or in a line of $\mathrm{p} 21^{-/-}$ mixed (129/Sv x B6) mice, derived from an unknown number of intercrosses, claim that p21 deficiency may have irrelevant or even protective effects on disease development 
[10-12], suggesting the existence of unknown strain-specific genetic interactions that modulate the accelerator activity of this genetic abnormality in autoimmunity.

There are multiple evidences indicating that p27 is an important regulator of clonal anergy of $\mathrm{T}$ lymphocytes $[13,14]$. In this sense, $\mathrm{p} 27$ is required for transplantation tolerance induced by costimulatory blockade [31]. However, $\mathrm{p} 27^{-/-}$mice have failed to develop autoimmune diseases even in a $(129 / \mathrm{Sv} \times \mathrm{B} 6)$ genetic background [15]. Accordingly, we have been unable to demonstrate the presence of high titres of circulating autoAbs and glomerulonephritis in almost all B6.p2 $7^{-/-}-\mathrm{hBcl}-2-$ B Tg mice analyzed here, despite an expansion in memory B and T cells being observed in these animals. Recent studies have shown the presence of increased serum levels of autoAbs and mild glomerular lesions in B6.hBcl-2-B Tg mice deficient in the $\mathrm{G}_{1} / \mathrm{S}$ cell cycle regulators E2F1 or E2F2, although the survival of these animals is similar to that of non-Tg controls $[32,33]$. Altogether, these and our present results indicate that the regulators of the $G_{1} / S$ transition of the cell cycle are hot spot targets for the control of lymphocyte tolerance. However, not all the regulators of this critical cell cycle check point appear to influence lymphocyte tolerance to the same extent, there existing a certain hierarchy in which each genetic defect of these regulators exhibits different potentials to promote systemic autoimmune diseases in cooperation with genetic abnormalities that prolong $\mathrm{B}$ cell survival (at least $\mathrm{Bcl}-2$ overexpression). In this hierarchy, the pro-autoimmune potential of p21deficiency in cooperation with B-cell $\mathrm{hBcl}-2$ overexpression is higher than that of E2F1 or E2F2 deficiency, which in turn is superior to that of $\mathrm{p} 27$ deficiency.

In addition to its anti-apoptotic activity, Bcl-2 is also involved in the control of cellular proliferation. In particular, the overexpression of Bcl-2 in lymphocytes or fibroblasts significantly delays the cell cycle entry of these cells after activation [29, 
30]. On the other hand, p21 may act as a survival factor in several cell types, including $\mathrm{T}$ lymphocytes [28]. Thus, epistatic interactions between p21 deficiency and Bcl-2 overexpression affecting the survival and/or proliferation of B cells can be involved in the induction of severe autoimmunity in B6.p2 $1^{-/-}$-hBcl-2-B Tg mice. However, the antiapoptotic and anti-proliferative effects of hBcl-2 overexpression in B cells from B6.hBcl-2-B Tg mice are not modified by the presence of the $p 21$ null mutation, indicating a dominant role of overexpressed Bcl-2 over p21 deficiency. Although p27 has been proposed as a critical mediator of the anti-proliferative function of Bcl-2 [30], our experiments clearly show that the proliferative defects observed in B cells overexpressing hBcl-2 are not restored by p27 deficiency. These results are fully in agreement with a recent report showing a similar cell cycle delay in anti-CD3 stimulated T cells from $\mathrm{hBcl}-2-\mathrm{T}$ Tg and $\mathrm{p} 27^{-/-}-\mathrm{hBcl}-2-\mathrm{T}$ Tg mice [21]. However, as our studies have been carried out on total B-cell populations, we cannot exclude the possibility that the interaction between p21 deficiency and Bcl-2 overexpression implicated in cell cycle progression and survival may be restricted to some minor subsets of activated/memory B cells (see below).

Consistent with a previous finding [7], our B6.p $21^{-/-}$mice exhibited an agedependent enlargement of memory $\mathrm{CD}^{+}{ }^{+} \mathrm{T}$-cell subpopulation, and this is more pronounced in B6.p21 $1^{-/-}-\mathrm{hBcl}-2-\mathrm{B}$ Tg mice developing a severe SLE. However, we observed that non-autoimmune B6.p2 $7^{-/-}$and B6.p2 $7^{-/-}$-hBcl-2-B Tg mice had increased numbers of $\mathrm{CD} 4{ }^{+} \mathrm{CD} 44^{\text {high }} \mathrm{CD} 62 \mathrm{~L}^{\text {low }} \mathrm{T}$ cells even at 2 months of age and at levels comparable to those of B6.p2 $1^{-/-}$-hBcl-2-B Tg mice. These data strongly suggest that the expansion of these memory $\mathrm{T}$ cells in B6.p2 $1^{-/-}-\mathrm{hBcl}-2-\mathrm{B} \mathrm{Tg}$ mice by itself is not sufficient to promote the disease. 
It has been demonstrated that Bcl-2 overexpression extends the lifetime of memory B cells [34]. Accordingly, high numbers of $\mathrm{B} 220^{+} \operatorname{IgM}^{-} \operatorname{IgD}^{-} \mathrm{CD} 138^{-}$memory B cell are found in B6.hBcl-2-B Tg mice even at 2 months of age. Parallel to the increase in memory $\mathrm{CD}^{+} \mathrm{T}$ cells, memory B cells are also expanded in B6.p2 $1^{-/-}$and B6.p2 $7^{-/-}$ mice. However, whereas the size of this B cell population in B6.p2 $7^{-/-}-\mathrm{hBcl}-2-\mathrm{B}$ Tg mice is similar to that of $\mathrm{B} 6 . \mathrm{hBcl}-2-\mathrm{B} \mathrm{Tg}$ mice, a synergistic interaction between $\mathrm{p} 21$ deficiency and Bcl-2 overexpression seems to regulate the number of memory B cells in B6.p21 $1^{-/-}-\mathrm{hBcl}-2-\mathrm{B} \mathrm{Tg}$ mice. This synergistic interaction may operate at two levels. First, and as in T cells [9], p21 can affect the proliferation of memory, but not naïve, B cells that survive activation-induced cell death (AICD) processes. Second, hBcl-2 overexpression can modulate the pro-apoptotic activity of Bim regulating the survival of memory B and autoAb-forming cells during AICD in vivo $[35,36]$. In this scenario, the abnormal expansion and/or survival of these B cells together with the increased number of memory $\mathrm{CD}^{+} \mathrm{T}$ cells may be the cause for the induction of SLE in B6.p2 $1^{-/-}-\mathrm{hBcl}-2-$ B Tg mice.

A careful analysis of B6.p2 $1^{-/-}-\mathrm{hBcl}-2-\mathrm{B} \mathrm{Tg}$ mice at the time of autopsy indicates that in addition to the development of a lupus-like autoimmune syndrome associated with an IgA nephropathy, these mice present B-cell LPD with a much higher incidence than B6.p21 $1^{-/-}$or B6.hBcl-2-B Tg mice. Histologically, these LPD can be classified as PLPD and immunoblastic B-cell lymphomas. The coexistence of both types of LPD in many animals strongly suggests that these lesions may represent different stages of the same B-cell malignancy. Despite the absence of autoimmunity in B6.p2 $7^{-/-}-\mathrm{hBcl}-2-\mathrm{B}$ Tg mice (present study), we have observed the development of B-cell LPD in these animals that shortened their lifespan (Santiuste I. et al, manuscript in preparation). In this regard, it has been shown that $\mathrm{p} 27^{-/-}$mice overexpressing $\mathrm{Bcl}-2$ in $\mathrm{T}$ lymphocytes 
spontaneously develop T-cell lymphomas with a high incidence [21]. At present, the mechanisms responsible for the development of B-cell LPD in B6.p2 $1^{-/-}-\mathrm{hBcl}-2-\mathrm{B}$ Tg mice are unknown. One possibility is that the same epistatic interaction between p21 deficiency and Bcl-2 overexpression promotes LPD in B6.p2 $1^{-/-}-\mathrm{hBcl}-2-\mathrm{B} \mathrm{Tg}$ mice independently of the autoimmune syndrome, as both B6.p2 $1^{-/-}$or B6.hBcl-2-B Tg mice develop with age B-cell malignancies without overt autoimmune diseases $[16,17,19]$. Additionally and/or alternatively, the development of B-cell LPD in B6.p2 $1^{-/-}$-hBcl-2-B Tg mice may be closely linked to the autoimmune process, secondary to the chronic activation of autoreactive B lymphocytes by non-tolerized $\mathrm{CD} 4{ }^{+} \mathrm{T}$ cells. In this regard, the spontaneous development of B-cell lymphomas is common in different lupus-prone mice, such as NZB, Fas or FasL deficient and interleukin-12 receptor beta2 deficient mice [37-40]. Experiments are in course to clarify this important question.

\section{Acknowledgements}

We thank Dr Dimitri Balomenos, Centro Nacional de Biotecnología, CSIC, Madrid, Spain, for mice and helpful suggestions, Dr Miguel A. Gonzalez-Gay, Hospital Universitario Marqués de Valdecilla, Santander, Spain for comments to the manuscript, Maria Aramburu, Natalia Cobo, Consuelo Agüeros, Lorena San Cosme, María Sanchez and Iván Gómez for technical assistance. This work was supported by grants from the Ministerio de Educación y Ciencia, Spain to RM (SAF2008-02042) and JM (BFU200907206), by grants REDINREN RD06/0016 from the Instituto de Salud Carlos III and from Fundación Eugenio Rodríguez Pascual, Spain to RM, from the Fundación Marqués de Valdecilla, Spain to JM (API-07/02), by a grant from the Swiss National Foundation for Scientific Research to SI. FG is supported by a pre-doctoral fellowship from the Instituto Danone, Spain. The authors have no conflicting financial interests. 


\section{References}

[1] Goodnow CC. Multistep pathogenesis of autoimmune disease. Cell 2007, 130: 2535.

[2] Marquina R, Díez MA, López-Hoyos M, Buelta L, Kuroki A, Kikuchi S, et al. Inhibition of B cell death causes the development of an IgA nephropathy in (New Zealand white x C57BL/6)F(1)-bcl-2 transgenic mice. J Immunol 2004, 172: 717785.

[3] Strasser A, Whittingham S, Vaux DL, Bath ML, Adams JM, Cory S, et al. Enforced BCL2 expression in B-lymphoid cells prolongs antibody responses and elicits autoimmune disease. Proc Natl Acad Sci USA 1991, 88: 8661-5.

[4] Bouillet P, Metcalf D, Huang DC, Tarlinton DM, Kay TW, Köntgen F, et al. Proapoptotic Bcl-2 relative Bim required for certain apoptotic responses, leukocyte homeostasis, and to preclude autoimmunity. Science 1999, 286: 1735-8.

[5] Bouillet P, Cory S, Zhang LC, Strasser A, Adams JM. Degenerative disorders caused by Bcl-2 deficiency are prevented by loss of its BH3-only antagonist Bim. Dev Cell 2001, 1: 645-53.

[6] Vidal S, Kono DH, Theofilopoulos AN. Loci predisposing to autoimmunity in MRL-Fas lpr and C57BL/6-Fas lpr mice. J Clin Invest 1998, 101: 696-702.

[7] Balomenos D, Martín-Caballero J, García MI, Prieto I, Flores JM, Serrano M, et al. The cell cycle inhibitor p21 controls T-cell proliferation and sex-linked lupus development. Nat Med 2000, 6: 171-6.

[8] Goulvestre C, Chéreau C, Nicco C, Mouthon L, Weill B, Batteux F. A mimic of p21WAF1/CIP1 ameliorates murine lupus. J Immunol 2005, 175: 6959-67.

[9] Arias CF, Ballesteros-Tato A, García MI, Martín-Caballero J, Flores JM, MartínezA C, et al. p21CIP1/WAF1 controls proliferation of activated/memory T cells and 
affects homeostasis and memory $\mathrm{T}$ cell responses. J Immunol 2007, 178: 2296306.

[10] Lawson BR, Kono DH, Theofilopoulos AN. Deletion of p21 (WAF-1/Cip1) does not induce systemic autoimmunity in female BXSB mice. J Immunol 2002, 168 : 5928-32.

[11] Lawson BR, Baccala R, Song J, Croft M, Kono DH, Theofilopoulos AN. Deficiency of the cyclin kinase inhibitor p21(WAF-1/CIP-1) promotes apoptosis of activated/memory $\mathrm{T}$ cells and inhibits spontaneous systemic autoimmunity. $\mathrm{J}$ Exp Med 2004, 199: 547-57.

[12] Santiago-Raber ML, Lawson BR, Dummer W, Barnhouse M, Koundouris S, Wilson CB, et al. Role of cyclin kinase inhibitor p21 in systemic autoimmunity. J Immunol 2001, 167: 4067-74.

[13] Boussiotis VA, Freeman GJ, Taylor PA, Berezovskaya A, Grass I, Blazar BR, et al. p27kip1 functions as an anergy factor inhibiting interleukin 2 transcription and clonal expansion of alloreactive human and mouse helper T lymphocytes. Nat Med 2000, 6: 290-7.

[14] Li L, Iwamoto Y, Berezovskaya A, Boussiotis VA. A pathway regulated by cell cycle inhibitor p27Kip1 and checkpoint inhibitor Smad3 is involved in the induction of T cell tolerance. Nat Immunol 2006, 7: 1157-65.

[15] Fero ML, Rivkin M, Tasch M, Porter P, Carow CE, Firpo E, et al. A syndrome of multiorgan hyperplasia with features of gigantism, tumorigenesis, and female sterility in p27(Kip1)-deficient mice. Cell 1996, 85: 733-44.

[16] Tsujimoto Y, Croce CM. Analysis of the structure, transcripts, and protein products of bcl-2, the gene involved in human follicular lymphoma. Proc Natl Acad Sci U S A 1986, 83: 5214-8. 
[17] McDonnell TJ, Korsmeyer SJ. Progression from lymphoid hyperplasia to highgrade malignant lymphoma in mice transgenic for the $t(14 ; 18)$. Nature 1991,349 : 254-6.

[18] Strasser A, Harris AW, Cory S. E-mu-bcl-2 transgene facilitates spontaneous transformation of early pre-B and immunoglobulin-secreting cells but not $\mathrm{T}$ cells. Oncogene 1993, 8: 1-9.

[19] Bhatia K, Fan S, Spangler G, Weintraub M, O'Connor PM, Judde JG, et al mutant p21 cyclin-dependent kinase inhibitor isolated from a Burkitt's lymphoma. Cancer Res 1995, 55: 1431-5.

[20] Martín-Caballero J, Flores JM, García-Palencia P, Serrano M. Tumor susceptibility of p21(Waf1/Cip1)-deficient mice. Cancer Res 2001, 61: 6234-8.

[21] Cheng N, van de Wetering CI, Knudson CM. p27 deficiency cooperates with Bcl-2 but not Bax to promote T-cell lymphoma. PLoS One 2008, 3: e1911.

[22] Brugarolas J, Chandrasekaran C, Gordon JI, Beach D, Jacks T, Hannon GJ. Radiation-induced cell cycle arrest compromised by p21 deficiency. Nature 1995, 377: $552-7$.

[23] González J, Tamayo E, Santiuste I, Marquina R, Buelta L, González-Gay MA, et al. $\mathrm{CD} 4^{+} \mathrm{CD} 25^{+} \mathrm{T}$ cell-dependent inhibition of autoimmunity in transgenic mice overexpressing human Bcl-2 in T lymphocytes. J Immunol 2007, 178: 2778-86.

[24] Grillot DA, Merino R, Pena JC, Fanslow WC, Finkelman FD, Thompson CB, et al. bcl-x exhibits regulated expression during B cell development and activation and modulates lymphocyte survival in transgenic mice. J Exp Med 1996, 183: 381-91.

[25] López-Hoyos M, Carrió R, Merino R, Buelta L, Izui S, Núñez G, et al. Constitutive expression of bcl-2 in B cells causes a lethal form of lupuslike autoimmune disease 
after induction of neonatal tolerance to H-2b alloantigens. J Exp Med 1996, 183: 2523-31

[26] Merino R, Iwamoto M, Gershwin ME, Izui S. The Yaa gene abrogates the major histocompatibility complex association of murine lupus in (NZB x BXSB)F1 hybrid mice. J Clin Invest 1994, 94: 521-5.

[27] Izui S, Higaki M, Morrow D, Merino R. The Y chromosome from autoimmune $\mathrm{BXSB} / \mathrm{MpJ}$ mice induces a lupus-like syndrome in (NZW x C57BL/6)F1 male mice, but not in C57BL/6 male mice. Eur J Immunol 1988, 18: 911-5.

[28] Maddika S, Ande SR, Panigrahi S, Paranjothy T, Weglarczyk K, Zuse A, et al. Cell survival, cell death and cell cycle pathways are interconnected: implications for cancer therapy. Drug Resist Updat 2007, 10: 13-29.

[29] Huang DC, O'Reilly LA, Strasser A, Cory S. The anti-apoptosis function of Bcl-2 can be genetically separated from its inhibitory effect on cell cycle entry. EMBO J 1997, 16: 4628-38.

[30] Vairo G, Soos TJ, Upton TM, Zalvide J, DeCaprio JA, Ewen ME, et al. Bcl-2 retards cell cycle entry through p27(Kip1), pRB relative p130, and altered E2F regulation. Mol Cell Biol 2000, 20: 4745-53.

[31] Rowell EA, Wang L, Hancock WW, Wells AD. The cyclin-dependent kinase inhibitor $\mathrm{p} 27 \mathrm{kip} 1$ is required for transplantation tolerance induced by costimulatory blockade. J Immunol 2006, 177: 5169-76.

[32] Marín MJ, García I, Peña M, Bolívar A, Zubiaga A, López-Hoyos M. E2F1-/C57BL/6 mice overexpressing a human Bcl-2 transgene in B cells develop a mild autoimmune syndrome. Ann N Y Acad Sci 2005, 1051: 156-65. 
[33] Marín-Vidalled MJ, Bolívar A, Zubiaga A, López-Hoyos M. The combined effect of BCL-2 over-expression and E2F2 deficiency induces an autoimmune syndrome in non-susceptible mouse strain C57BL/6. Autoimmunity 2010, 43: 111-20.

[34] Nuñez G, Hockenbery D, McDonnell TJ, Sorensen CM, Korsmeyer SJ. Bcl-2 maintains B cell memory. Nature 1991, 353: 71-3.

[35] Hande S, Notidis E, Manser T. Bcl-2 obstructs negative selection of autoreactive, hypermutated antibody V regions during memory B cell development. Immunity 1998, 8: 189-98.

[36] Fischer SF, Bouillet P, O'Donnell K, Light A, Tarlinton DM, Strasser A. Proapoptotic $\mathrm{BH} 3$-only protein Bim is essential for developmentally programmed death of germinal center-derived memory B cells and antibody-forming cells. Blood 2007, 110: 3978-84.

[37] Bielschowsky M, Bielschowsky F. Reaction of the reticular tissue of mice with autoimmune haemolytic anaemia to 2-aminofluorene. Nature 1962, 194: 692.

[38] Marti GE, Metcalf RA, Raveche E. The natural history of a lymphoproliferative disorder in aged NZB mice. Curr Top Microbiol Immunol 1995, 194: 117-26.

[39] Davidson WF, Giese T, Fredrickson TN. Spontaneous development of plasmacytoid tumors in mice with defective Fas-Fas ligand interactions. J Exp Med 1998, 187: 1825-38.

[40] Airoldi I, Di Carlo E, Cocco C, Sorrentino C, Fais F, Cilli M, et al. Lack of Il12rb2 signaling predisposes to spontaneous autoimmunity and malignancy. Blood 2005, 106: 3846-53. 


\section{Figure Legends}

Figure 1. Survival and proliferation of B cells from B6 mice overexpressing hBcl-2 in B cells and deficient in p21 or p27. A) Purified B cells from different strains of mice were cultured in triplicates in 96-well flat-bottomed plates at a concentration of $10^{6}$ cells/ml in RPMI 10\% FCS. From day 1 to 10 , viability of spleen B cells was assessed by trypan blue exclusion. Results are representative of two separate experiments. B) 2 month-old mice were injected ip with PBS (upper panels) or $2 \mathrm{mg}$ of dexamethasone (lower panels). The elimination of $\mathrm{B} 220^{\text {low }} \operatorname{IgM}^{-}$pre-B and $\mathrm{B} 220^{\text {low }} \operatorname{IgM}^{+}$immature $\mathrm{B}$ cells was evaluated by flow cytometry $48 \mathrm{hrs}$ after treatment. The mean $\pm \mathrm{SD}$ of the percentages of $\mathrm{B} 220^{\text {low }} \operatorname{IgM}^{-}$pre-B (upper left) and $\mathrm{B} 220^{\text {low }} \operatorname{IgM}^{+}$immature B cells (bottom right) in the different experimental groups ( 3 mice/group) are indicated in each panel. Statistic differences between $\mathrm{hBcl}-2 \mathrm{Tg}$ and non-Tg dexamethasone-treated animals are indicated as follow: ${ }^{*} \mathrm{p}<0.01,{ }^{*} \mathrm{p}<0.001$. Results are representative of three separate experiments. C) CFSE-labelled B cells $\left(2 \times 10^{5}\right)$ from the different strains of mice were stimulated during $48 \mathrm{hrs}$ with $20 \mu \mathrm{g} / \mathrm{m}$ LPS or $20 \mu \mathrm{g} / \mathrm{ml}$ of anti-IgM antibody. Cell division was analyzed by flow cytometry according to the CFSE intensity dilution. Results, representative of two separate experiments, are expressed as the mean percentage \pm SD (3 mice/group) of proliferating cells.

Figure 2. Production of autoAbs in B6 mice overexpressing hBcl-2 in B cells and deficient in $\mathrm{p} 21$ or p27. A and B) Serum levels of $\operatorname{IgA}$ and IgG anti-DNA autoAbs and gp70 IC (A) and of total $\operatorname{IgA}$ and $\operatorname{IgG}(\mathbf{B})$ in the mentioned mouse strains at 6 months of age. Values of individual mice are expressed. Bars represent the mean value of each examination. 
Figure 3. Mortality curve of B6 mice overexpressing hBcl-2 in B cells and deficient in p21.

Figure 4. Development of glomerulonephritis in B6 mice overexpressing hBcl-2 in B cells and deficient in $\mathrm{p} 21$ or p27. A) Glomerulonephritis score in the different strains of mice at the time of autopsy (B6.p21 $1^{-/-}-\mathrm{hBcl}-2-\mathrm{B} \mathrm{Tg}$ mice) or at 14-16 months of age (other groups). Values of individual mice are expressed. Bars represent the mean value of each group. B) Representative histological appearance of glomeruli (x40) from B6wt, B6.p2 $1^{-/-}$and B6.hBcl-2-B Tg mice at 14-16 months of age and from B6.p21 $1^{-/-}-\mathrm{hBcl}-$ 2-B Tg mice at the time of autopsy, stained with hematoxilin-eosin or Masson trichrome (two upper panels). Presence of $\operatorname{IgG}$ and IgA deposits (two lower panels) in the glomeruli of B6-wt, B6.p21 $1^{-/}$and B6.hBcl-2-B Tg mice at 14-16 months of age and from B6.p2 $1^{-/-}-\mathrm{hBcl}-2-\mathrm{B} \mathrm{Tg}$ mice at the time of autopsy (x40). C) Representative histological appearance of glomeruli (x40) from 14 month-old B6.p27 $7^{-/}$and B6.p2 $7^{-/}$hBcl-2-B Tg mice stained with hematoxilin-eosin or Masson trichrome.

Figure 5. Development of LPD in B6 mice overexpressing hBcl-2 in B cells and deficient in p21. A) PLPD in a lymph node from a 10 month-old B6.p2 $1^{-/-}$-hBcl-2-B Tg mice (x40). B) PLPD in the lymph node of a 10 month-old B6.p2 $1^{-/-}$mice $(x 40)$. C) Immunoblastic B-cell lymphoma in a 14 month-old B6.p2 $1^{-/-}-\mathrm{hBcl}-2-\mathrm{B}$ Tg mice (x100) showing an aberrant mitosis (red arrow and squared amplification in the bottom left corner). D) Starry sky pattern of the immunoblastic B-cell lymphoma showed in B (x20). E) PLPD infiltrates in the kidney of an 18 month-old B6.p2 $1^{-/-}-\mathrm{hBcl}-2-\mathrm{B}$ Tg mice (x40). F) Immunoblastic B-cell lymphoma in the lymph node of a 18 month-old B6.hBcl-2-B Tg mice (x40) showing areas with PLPD (red arrows). 
Table 1: Distribution of naïve and memory B and $\mathrm{CD}^{+} \mathrm{T}$ cell populations in $\mathrm{p} 21$ and $\mathrm{p} 27$ deficient mice in the context of hBc-2 B-cell overexpression.

\begin{tabular}{|c|c|c|c|c|c|c|c|}
\hline \multirow[b]{2}{*}{ Mice } & \multirow[b]{2}{*}{ Age } & \multicolumn{2}{|c|}{ B Cells } & \multicolumn{2}{|c|}{$\mathrm{CD}^{+}$Cells } & \multicolumn{2}{|c|}{$\mathrm{CD}^{+}$Cells } \\
\hline & & $\mathrm{B} 220^{+}$ & memory & naïve & memory & naïve & memory \\
\hline \multirow[t]{2}{*}{ B6-wt } & 2 & $36.4 \pm 8.9$ & $2.3 \pm 0.5$ & $10.8 \pm 4.9$ & $5.3 \pm 1.1$ & $7.9 \pm 3.2$ & $1.8 \pm 0.3$ \\
\hline & 8 & $57.1 \pm 10.5$ & $4.9 \pm 2.4$ & $11.9 \pm 5.3$ & $8.1 \pm 1.5$ & $11.6 \pm 5.9$ & $2.1 \pm 1.8$ \\
\hline \multirow[t]{2}{*}{ B6.p21 } & 2 & $44.1 \pm 17.1$ & $3.9 \pm 1.9$ & $11.3 \pm 4.8$ & $8.3 \pm 4.1$ & $7.9 \pm 3.1$ & $1.9 \pm 1.5$ \\
\hline & 8 & $35.6 \pm 15.4$ & $7.1 \pm 3.1$ & $6.4 \pm 2.8$ & $14.1 \pm 3.9$ & $6.4 \pm 2.7$ & $2.2 \pm 1.0$ \\
\hline \multirow[t]{2}{*}{ B6.hBcl-2-B Tg } & 2 & $166.8 \pm 56.5$ & $16.8 \pm 6.8$ & $14.1 \pm 3.2$ & $6.5 \pm 1.0$ & $13.1 \pm 3.2$ & $2.1 \pm 0.9$ \\
\hline & 8 & $138.8 \pm 66.2$ & $22.8 \pm 8.4$ & $14.8 \pm 5.4$ & $10.1 \pm 3.7$ & $14.5 \pm 6.3$ & $2.8 \pm 1.8$ \\
\hline \multirow[t]{2}{*}{ B6.p2 $1^{-/-}-\mathrm{hBcl}-2-\mathrm{B} \mathrm{Tg}$} & 2 & $206.4 \pm 42.8$ & $31.1 \pm 9.3$ & $12.2 \pm 5.6$ & $15.1 \pm 7.7$ & $11.1 \pm 3.3$ & $3.9 \pm 1.1$ \\
\hline & 8 & $220.6 \pm 38.5$ & $41.5 \pm 10.1$ & $7.6 \pm 3.7$ & $22.5 \pm 7.8$ & $7.8 \pm 4.2$ & $3.4 \pm 1.4$ \\
\hline \multirow[t]{2}{*}{ B6.p2 $7^{-/-}$} & 2 & $66.2 \pm 12.9$ & $4.4 \pm 2.2$ & $19.9 \pm 8.2$ & $18.1 \pm 8.2$ & $23.1 \pm 7.1$ & $5.9 \pm 3.4$ \\
\hline & 8 & $104.5 \pm 39.3$ & $17.3 \pm 6.1$ & $7.2 \pm 3.4$ & $18.4 \pm 5.7$ & $8.3 \pm 3.7$ & $5.4 \pm 2.3$ \\
\hline \multirow[t]{2}{*}{ B6.p27//- $\mathrm{hBcl}-2-\mathrm{B} \mathrm{Tg}$} & 2 & $137.7 \pm 50.1$ & $16.4 \pm 7.5$ & $23.4 \pm 4.6$ & $21.9 \pm 8.1$ & $28.4 \pm 6.3$ & $6.2 \pm 1.8$ \\
\hline & 8 & $116.6 \pm 32.8$ & $29.2 \pm 7.1$ & $5.1 \pm 2.7$ & $23.8 \pm 8.9$ & $6.0 \pm 2.3$ & $6.7 \pm 2.7$ \\
\hline
\end{tabular}

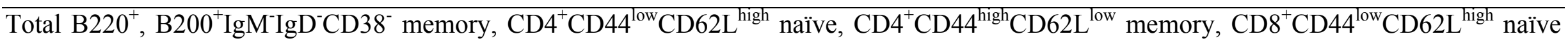
and $\mathrm{CD} 8{ }^{+} \mathrm{CD} 44^{\text {high }} \mathrm{CD} 62 \mathrm{~L}^{\text {low }}$ memory cells were evaluated in the spleen of 2 and 8 month-old mice by flow cytometry. Results from 6-8 mice/group are expressed as the mean $\pm \mathrm{SD}$ of the number of cells of each population. 
Table 2: Increased incidence of B-cell malignancies in B6.p2 $1^{-/-}-\mathrm{hBcl}-2-\mathrm{B}$ $\operatorname{Tg}$ mice.

\begin{tabular}{lccc}
\hline Mice & Type & $8-10$ months & 18 months \\
\hline \multirow{2}{*}{ B6-wt } & PLPD & $0 / 16(0 \%)$ & $0 / 12(0 \%)$ \\
& B-cell lymphoma & $0 / 16(0 \%)$ & $0 / 12(0 \%)$ \\
B6.p21 $1^{-/-}$ & PLPD & $1 / 14(7.1 \%)$ & $8 / 43(18.6 \%)$ \\
& B-cell lymphoma & $0 / 14(0 \%)$ & $1 / 43(2.3 \%)$ \\
B6.hBcl-2-B Tg & PLPD & $0 / 18(0 \%)$ & $0 / 24(0 \%)$ \\
& B-cell lymphoma & $0 / 18(0 \%)$ & $4 / 24(16.7 \%)$ \\
B6.p21 $1^{-/-}$-hBcl-2-B & PLPD & $5 / 16(31.3 \%)$ & $4 / 26(15.4 \%)$ \\
& B-cell lymphoma & $7 / 16(43.8 \%)$ & $18 / 26(69.2 \%)$
\end{tabular}

$\overline{\text { Groups of the different mouse strains were sacrificed at 8-10 and } 18 \text { months }}$ of age. Sections of major organs were included in paraffin and stained with hematoxilin-eosin. The presence of LPD, either PLPD or B-cell lymphoma, was evaluated by two pathologists. Under the PLPD group, we included animals that presented only this type of LPD. Under the B-cell lymphoma group, we included animals that presented this type of LPD independently of the coexistence of PLPD. 

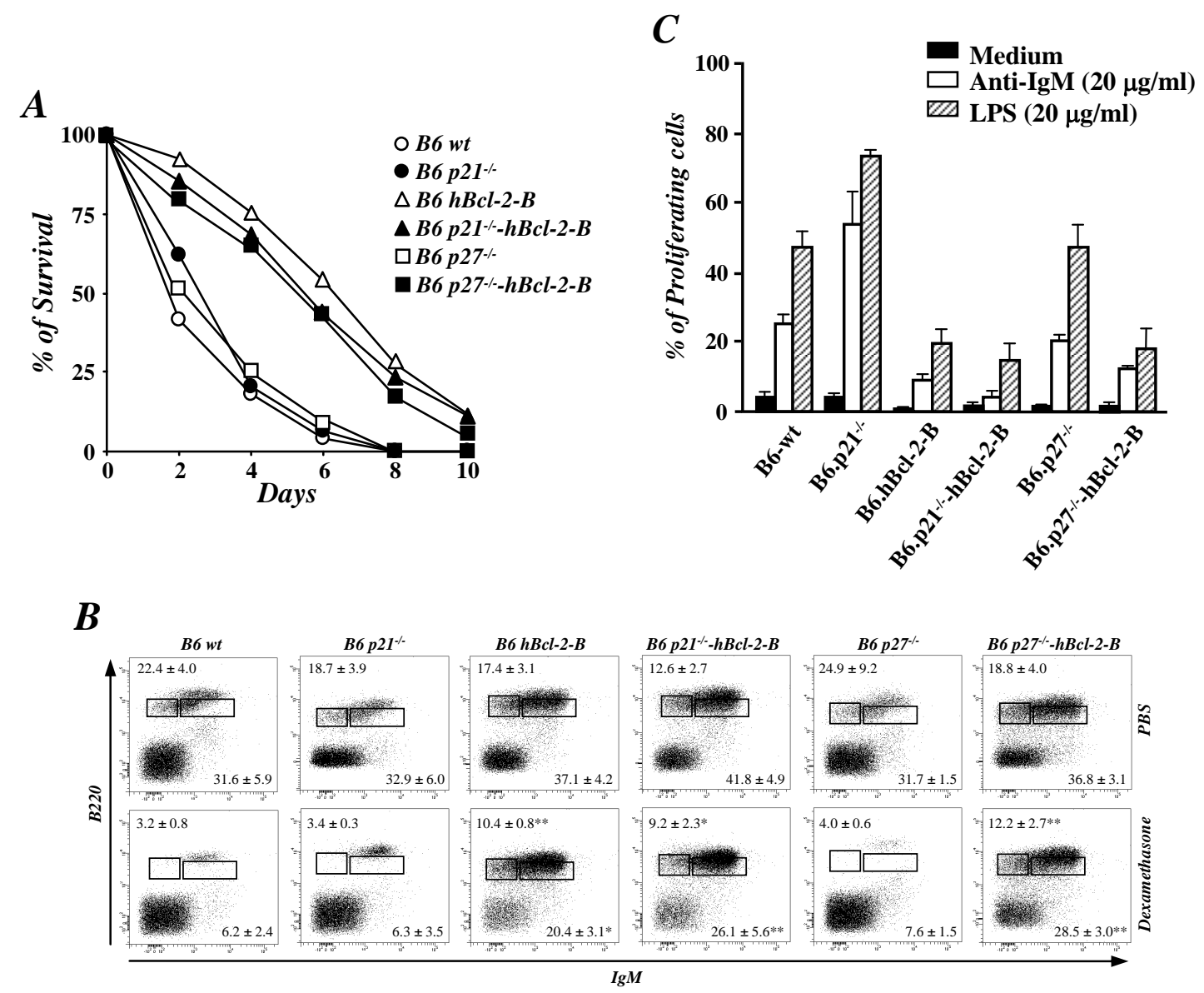
A
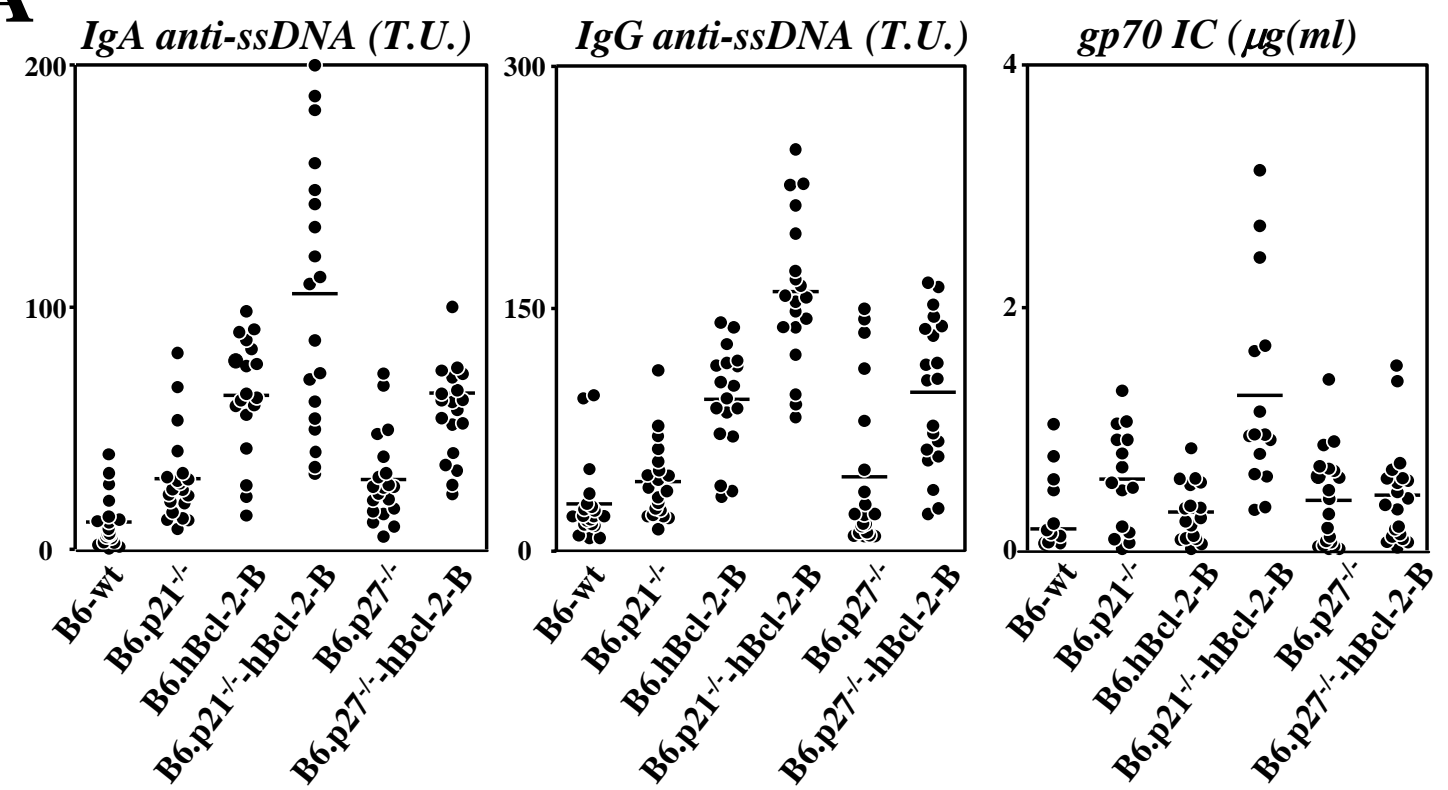

B
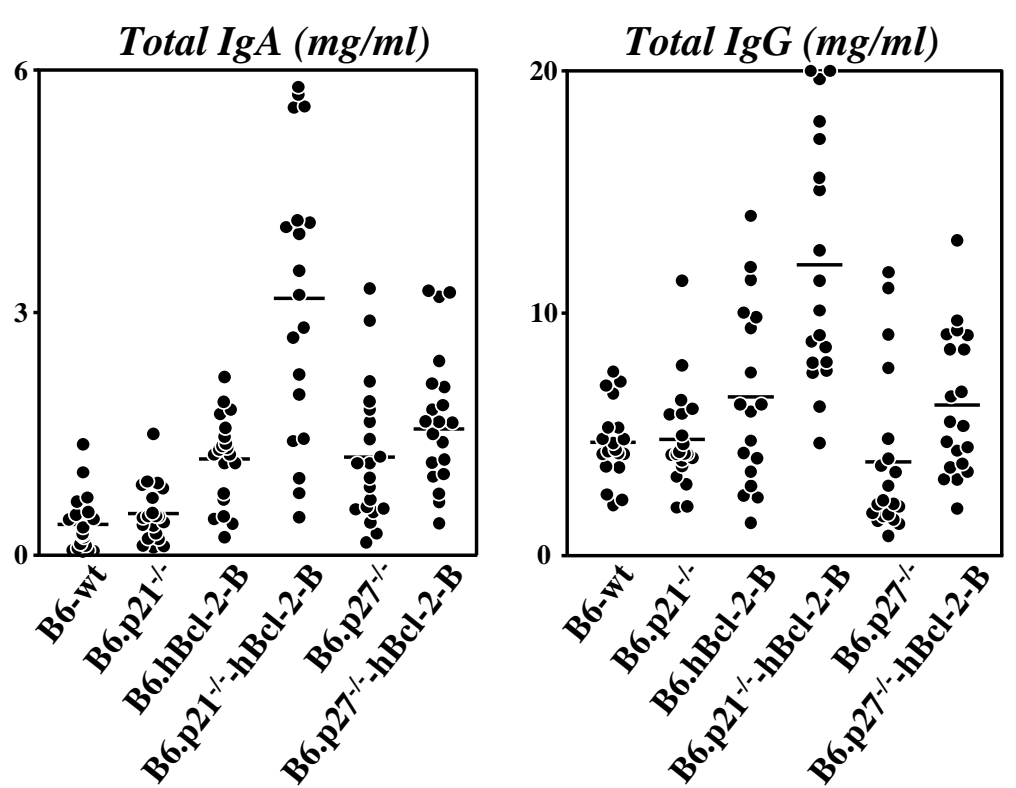

Figure 2 


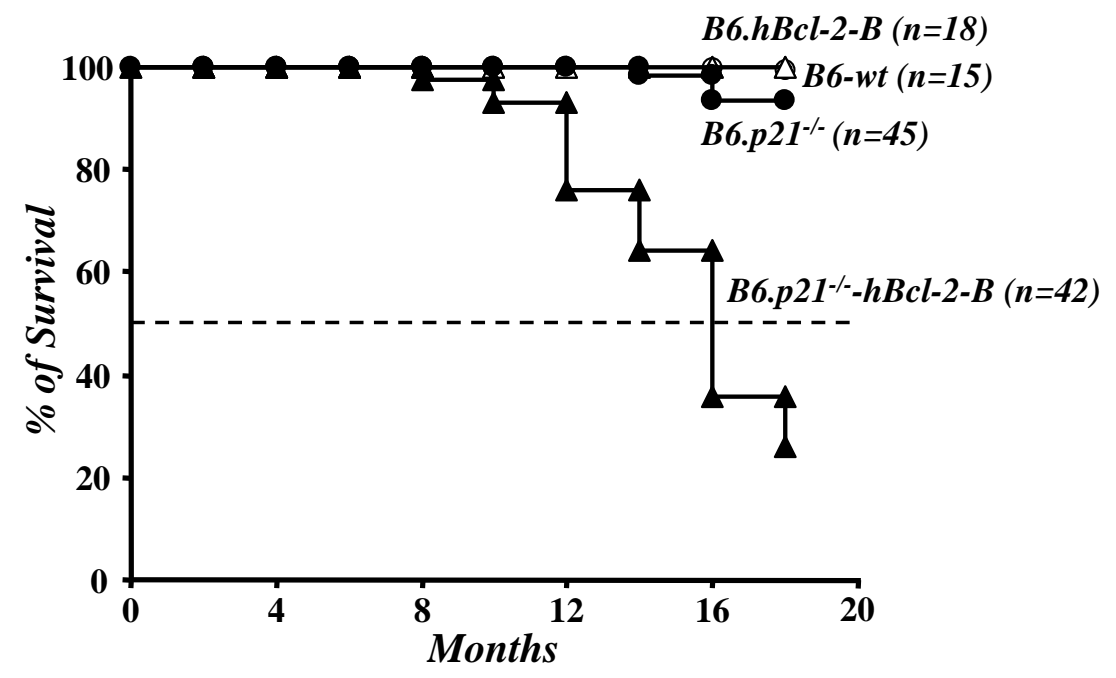

Figure 3 

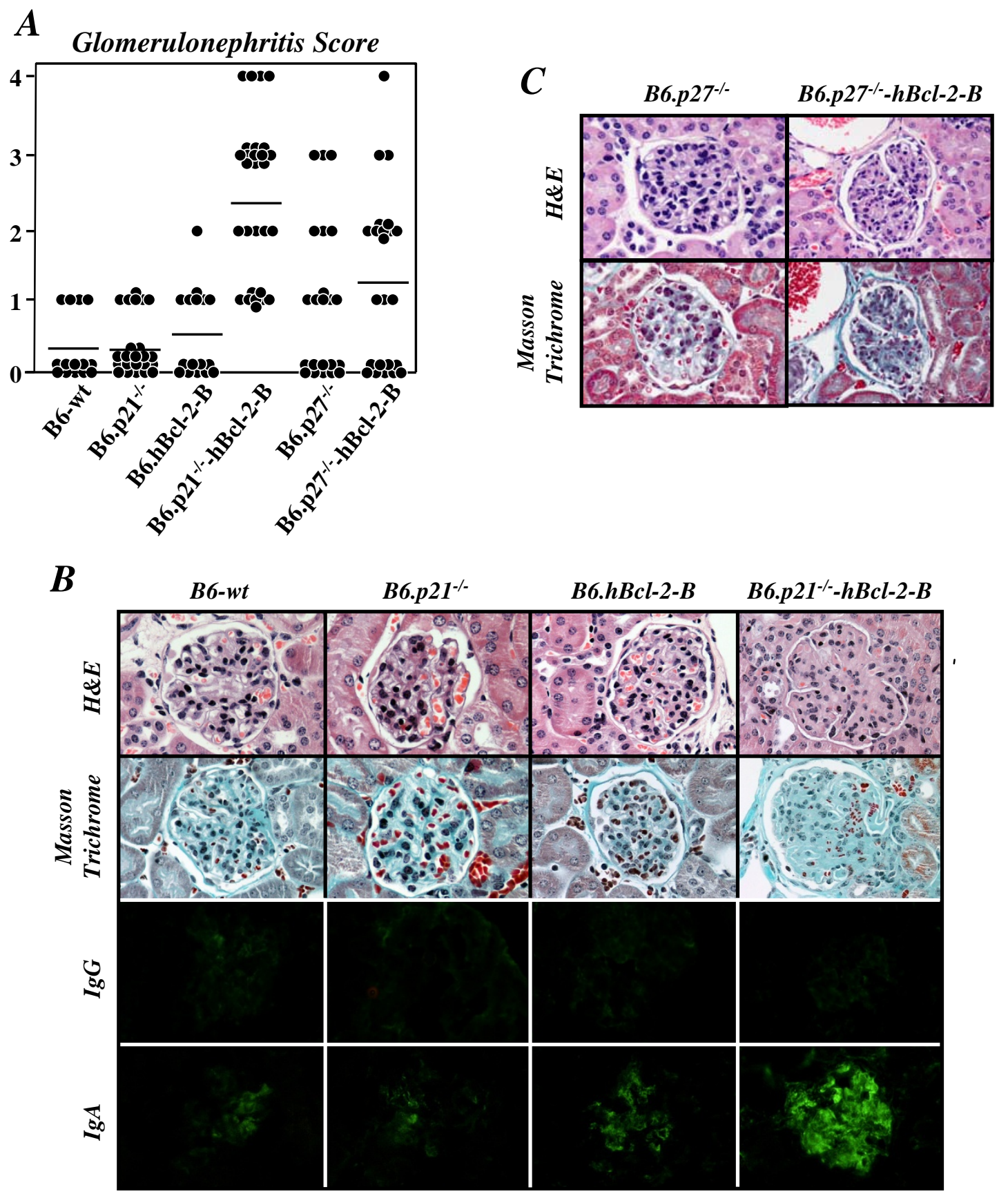

Figure 4 


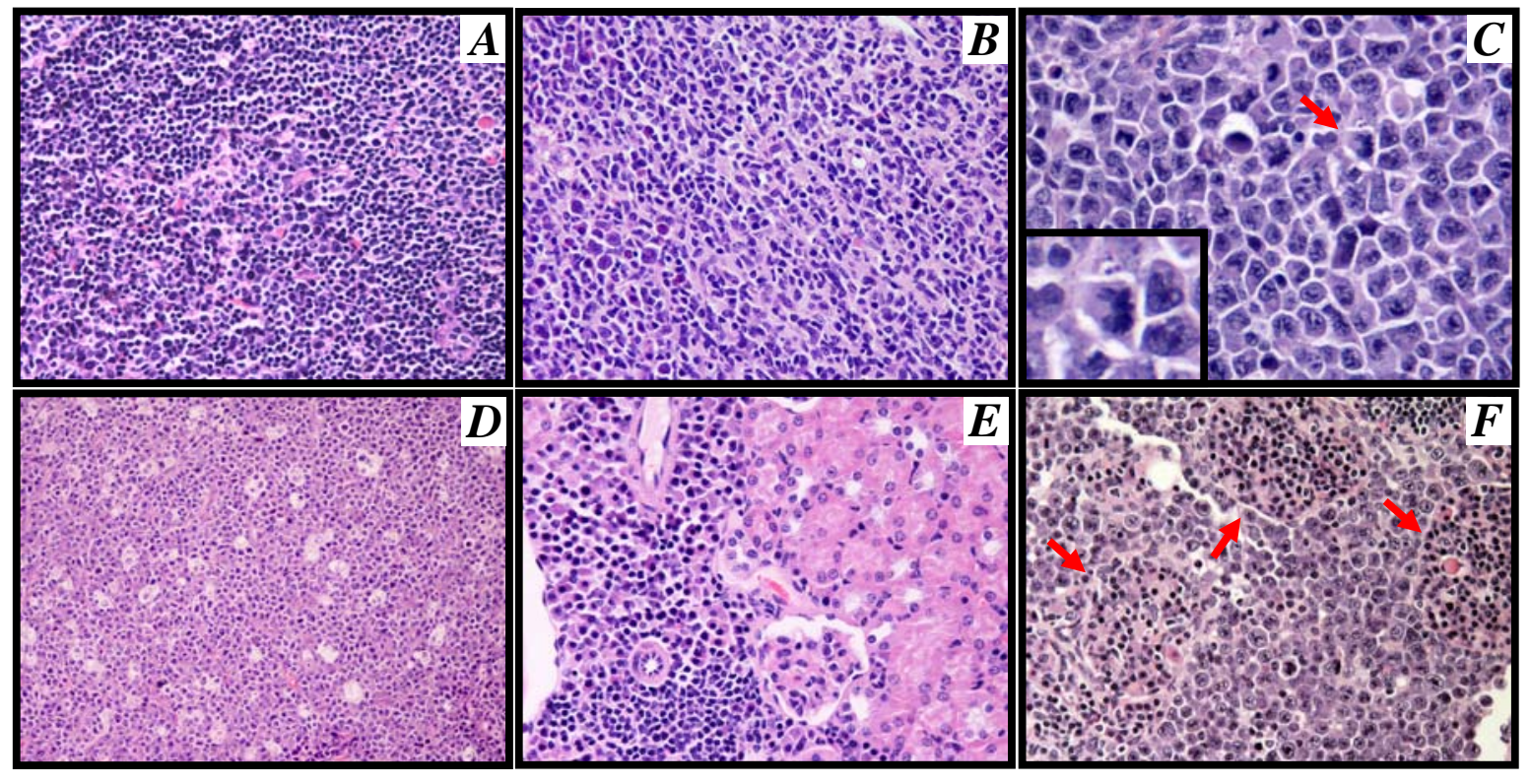

Figure 5 